\title{
Systemic Risk in Major Public Contracts
}

Katherine Bloomfield, Terry Williams, Chris Bovis, Yasmin Merali.

The University of Hull, Cottingham Road, Hull, HU6 7RX, UK.

\begin{abstract}
This paper presents a novel approach to the characterisation of "systemic risk" in the context of public sector procurement and contracting. We argue that contemporary risk management practices in project and programme management exhibit a number of limitations; this is particularly relevant to public sector contracting which, the authors postulate, would benefit from more sophisticated practices that are capable of dealing with risk 'systemicity'. Drawing on a sample of public sector procurement exercises commissioned by the UK Ministry of Defence (MoD), the paper presents a multi-method approach positioned towards increasing our understanding of complex outsourcing contracts. The results suggest a need for more appropriate methods of risk analysis, and discusses the practical implications.
\end{abstract}

Key words: projects, contracts, systemic risk, public sector, front-end, outsourcing.

\section{The front-end of projects}

The way that businesses operate is becoming increasingly project-based as organisations seek to deliver products and services on time, within scope and to budget. Midler (1995) coined the term 'projectification' to describe the transition from the classical functional organisation to project coordination and autonomous and project teams at the Renault group. The value associated with aggregated project-spend across the world resides within the billion-dollar bracket and concerns the construction of new capital assets, carrying out unique large-scale enterprises or developing new technological products. More than $20 \%$ of global economic activity takes place in projects: $23 \%$ of the $\$ 75$ trillion global GDP is gross fixed capital formation according to the World Bank (2018) (figures relate to 2016).

Within the public sector, projects and programmes are the key instruments used to realise policies, deliver transformational policy change and build new systems, increasingly with the support of the private sector 
to execute the work. The Chief Executive's foreword to the UK government Infrastructure and Projects Authority (IPA) annual report emphasises this; it begins - "Projects and programmes are the means by which government policies are made real; their successful implementation is vital to our economic wellbeing" (IPA, 2018). To emphasise the point, the UK Government Major Projects Portfolio, which encapsulates only the most important projects within government (circa. 140 projects), overseen by the IPA, has a total lifetime cost of $£ 455.5 b n$ (IPA, 2017).

It has become increasingly clear that the front-end of a project is the critical area, which forms the basis of success or failure for the project (Edkins et al., 2013). It is at this stage where the strategic intentions of the permanent organisation are translated into a plan of action and then, frequently, passed to a third party to execute. Morris (2011, page 6) for example describes how "data shows that most of the factors which seriously affect ... project outcome, for good or ill, will have been built-in to the front-end definitional decisions". Having said this, there is little published about the front-end. Edkins et al. (2013, page 71) emphasise this by saying “....our understanding of the role of such 'front-end project management' is not well documented in the literature, despite evidence of the importance of the frontend-that many of the things that cause projects not to succeed have their origins in decisions made in the project's front-end and that the front-end is the part of the project that has the greatest opportunity for creating value-and that, despite its importance, 'front-end' management issues, responsibilities, roles and actions are too often ignored by official project management guidance".

The fundamental purpose of a project is to execute important action or actions for the organisation, arising from the strategy of the organisation. Narayanan and DeFillippi (2012) provide a brief overview of recent studies about the strategic orientation of project management and the role of organisational strategy in shaping project management practices. However, there is a well-known tendency of projects to develop a "life of their own" (Keil, 1995 and Keil and Mähring, 2010) and concentrate on the delivery of the planned project outputs rather than the desired outcomes. Indeed, this has led to a whole discipline of "benefits management" (Breese et al., 2015) to work towards defining and maintaining the alignment of the project to its desired outcomes or aims or "benefits", although the implementation of this discipline seems at best patchy (PMI 2017). Aligning project outputs with the benefits desired by the organisation becomes more complex when the immediate benefits of the project are considered alongside their longer-term impacts, relevance and sustainability, as described in the Samset (2010) goals management approach which is used by various super-national authorities to develop their benefits frameworks. 
One paper that encapsulates the key themes within the front-end is Williams and Samset (2010). They consider in particular the alignment between organisational strategies and the project concept, and preparation for the turbulence within the project environment, including the maintenance of this strategic alignment. They also look at key themes including the issue of how to deal with complexity, in particular systemicity (see an early discussion by Eden et al., 2000) and interrelatedness within project decisions; the issue of how to deal with the ambiguity implicit in all major projects; the (well-researched) issues of psychological and political biases within estimation of benefits and costs (e.g. Flyvbjerg et al., 2003); consideration of the social geography and politics within decision-making groups.

Williams et al. (2018) describe a temporally ordered structure of generic processes that constitute the "front-end" and show how these fit together as a coherent whole. These start from the preliminaries to the initiative, then the project purpose (for various stakeholders), the initial analysis and scenario analysis; the analysis of alternatives and choice of project concept; assessment of the project (scope; estimation of cost, benefits and schedule; risk; technology \& sustainability; and the project delivery system), finishing with setting up the project execution (finance, governance, and contracts). Key to this set of stages for the purposes of this current paper, once the project purpose and concept are understood, are the risk assessment of the project, and the development of a contract which comprehends and governs those risks.

Of particular interest are projects that entail outsourcing of some, or all components to an external party. The conditions, constraints and provisions for such arrangements are enshrined in the contractual relationship between the procurer and the vendor (since we are only dealing with public projects, for terminological clarity within this paper, we will denote these as being the 'contracting authority' and the 'contractor' respectively). The contractual arrangements are thus critical in influencing project trajectories and risk profiles, but to date have received little attention in the mainstream project management literature. We shall look at the current state of risk assessment first, before moving onto the case for contracts.

\section{Projects and risk analysis}


Risks are identified and managed in practice in some well-established conventional forms. We distinguish between "uncertainties" and "risks": here we are referring to "uncertainties" as anything that is uncertain; to be relevant, the uncertainty should have an impact upon a project; a "risk" is the combination of the uncertainty and its potential impact upon the project. The formal recognition of risk management in projects emerged in the 1980's; risk registers, essentially lists of individual risk-items, became commonplace (Williams 1994). While the practice has continued to mature, there are still currently four issues with the practice of project risk management that will concern us in this paper.

Firstly, development still often reflects the dependence on risk registers as a tick-box exercise, with little recognition of the interdependence or systemicity within risks (Williams 2017). The Project Management Institute (2013) body of knowledge makes only a brief cryptic mention of the existence of methods to deal with inter-relatedness. ISO 31000 has no advice on aggregating, splitting or combining risks (Leitch, 2011). The UK Association of Project Management's Guide on Project Risk Analysis and Management (2004) has an Appendix on the issue; but later publications such as their guide on "Prioritising Project Risks" (Association of Project Management 2008) is clearly geared towards understanding and prioritising individual risks. Having said this, we are interested in understanding the overall risk to a project rather than only individual risks, and standard methodology is starting recognise that looking at overall risk is needed, with both the PMI's Practice Standard for Project Risk Management (Project Management Institute 2009) and the UK Association for Project Management (2012) Body of Knowledge looking at risks at both the individual risk level and "overall project risk" level.

Secondly, the idea of a uniform concept of "uncertainty" is too simplistic. To start with, there is a widespread division of the idea of uncertainty into "aleatoric" (relating to a situation which is intrinsically uncertain but where the uncertainty parameters are known, such as coin-tossing or rolling dice), and "epistemic" (where it is understood by the project evaluator to be uncertainty, but where there is not full knowledge about the situation to be able to analyse the uncertainty, such as where there is new development, or where uncertainty parameters are unknown); in the modern literature, Shafer (1976) gave an early exposition of this followed by Oakes (1986). These types of uncertainty are not only different in nature, but the actions that need to be taken to address the uncertainty are quite different (in the case of epistemic risks, more knowledge is needed, such as by research or prototypes, or better understanding; in the case of aleatoric risks, action may be more geared to monitoring and control). This can also be taken further into the well-known division of knowns and unknowns, as made famous by US Secretary of 
Defense Donald Rumsfeld (Department of Defense, 2002). A structured format for this is given in the Call for Papers for this issue (International Institute of Forecasters 2018), which divides uncertainties into four categories: known/knowns (aleatoric: for projects, this will include well-known uncertainties for which the conventional techniques of risk analysis can be applied, such as cost or resource uncertainties), known/unknowns (risks that we can envisage but with unusual or special circumstances, such as project variables that come outside the expected historical pattern), unknown/knowns (issues of judgemental, behavioural and organisational biases in projects), and unknown/unknowns or "black swans" (Taleb, 2008) (large-impact, hard-to-predict, rare events, such as the financial crash). Uncertainties encountered in projects can thus come in any of these categories and preparation for the project has to consider all of them; while this seems contradictory for "unknown unknowns", works such as Ramasesh and Browning (2014) seek out "knowable unknown-unknowns" (uncertainties which could be foreseen but for some reason are not yet: Ramasesh and Browning quote the baggage-handling system at Denver Airport as an example, page 191).

Thirdly, risk management practice does not always recognise the human component of many of these risks. Or, even if the root-cause risks are not caused by the human nature of projects ( $O^{\prime}$ Leary and Williams, 2013), then risks can set up causal chains which form feedback loops involving or even exacerbated through human response to project perturbations. These can include management responses to problems in projects such as increasing project parallelism, and the feedback which is why such actions sometimes have apparently counter-intuitive effects (Eden et al., 2005), or responses from the project workforce as they become disillusioned as work gets changed or continuously questioned, or rework increases. This both causes and is caused by the "issues with other groups, confusion, organizational conflict, sinking team spirit, and fading commitment" (Thamhain, 2013).

Fourthly, often conventional risk management practice is not undertaken in a way that is adequate to deal with the complexity of major, particularly public, projects: "in planning projects, government does not always take time to understand the complexity and, as a result, over-estimates its ability to deal with the challenges" (National Audit Office, 2013, page 6). This is for a number of reasons, two of which are the two points above: the treatment of risks individually, and the lack of attention to the human aspect of projects. Taking the project complexity analysis of Geraldi et al. (2011), who try to define project complexity by five dimensions: structural, uncertainty, dynamics, pace and socio-political, Williams (2017) looks at the implications for project risk analysis. This concludes that a systemic view of risk needs to be 
taken to deal with the structural complexity, including feedback loops, and the human reactions to events and socio-economic complexity need to be accounted for in assessing the causal chains and analysing the risk.

\section{Contract risk}

Whilst risk management is accounted for throughout the entire cycle of a project (from the initial generation of a concept through to its closure), the aforementioned inadequacies of the tools and methods adopted by project managers suggest that new considerations should be taken into account when dealing with complex cases. Public sector projects, like many major projects, are often underpinned by a formal contract that binds the contracting parties to a set of legal obligations, the intent of which is to correspond with, and drive the desired outcomes of the project. The contract is constructed to legally enforce a set of mutually agreed terms and conditions (T\&Cs) and acts as a fundamental reference point for the contracting parties throughout the entire duration of the project.

Such reference to the contract serves as a sure reminder of the responsibilities of each party, and in this sense, assures the parties of the risk protection measures in place. Broadly, each party has its own overarching concern relating to the onset of contract risk. The contracting authority's ultimate contract risk relates to the probability of losses incurred, which may result from the contractor's failure to perform its contractual obligations. The contracting authority however, may also be susceptible to contract risk where the contract and/or its supporting documentation is defective or unable to be legally enforced, that is, it must be: complete, unambiguous, capable of acceptance, and, constructed to be bound by acceptance. If the contract has been poorly written, the contracting authority may become liable on the grounds of organisational misconduct.

Conversely, the contractor's fundamental concern reflects the likelihood of the contracting authority reneging on the contract. The contracting authority may fail to fulfil its contractual obligations, such as its binding obligation to pay the contractor in return for its contractual performance. By considering the key actors of a contractual agreement, it would appear that contract risk may often amount to a dispute, requiring legal intervention. Additionally, contract risk may also encompass the burden that these repercussions may have on either contracting party (e.g. when remedying a breach of contract, such as in rescission and/or damages). 
As a term, contract risk appears to be undefined by any legal standards. Haapio and Siedel (2017) infer that the definition of contract risk is determined by context, referring to the identity of the contracting parties - whether they represent a company, a department or a project. Whilst context provides value for when understanding contract risk, it can be argued that every party to a contract shares a common interest in the ultimate outcome of the contract. Haapio and Siedel (2017) define "contract risk" as a risk, or set of risks that have the capacity to exacerbate a contract to the extent that it deviates away from the expected outcomes of either party. Whilst contract risk does encompass these features, the definition fails to consider the interdependencies or systemicity of risk within the contract architecture, which may lead to contract risk materialising.

Whilst definitions of contract risk appear to account for the shortfall of a contract in reaching its intended outcomes, they fail to consider the underlying components of risk, which may influence these undesirable outcomes. Aside from contract risk, other risks found within a contract can be identified and categorised as encompassing a range of forms, which can vary in severity and frequency, and have the capacity to impact negatively on either party. Miller and Lessard (2001) devise a taxonomy of risks in Large Engineering Projects and label these as: market-related risks; market and financial risk, completion risks; technical, construction and operational risks, and, institutional risks; regulatory, social-acceptability risks and sovereign risks. Adopting a similar risk categorising approach for contracting, we devise a risk taxonomy to account for: information, relational, performance and finance risks, as well as contract risk.

\section{Systemic risk}

Categorising risk enables project managers to identify, pre-empt, track and address the individual riskitems that are associated with a project (Miller and Lessard, 2001). As with the project, the contract must be able to govern these risks and endeavour to protect the contracting parties against the materialisation of harmful risk. Unfortunately, often, these risks are only considered and managed independently from one another, with little consideration given to the complex and dynamic interactions of risks that may unfold across the entire contract. Often, the identified failure of one risk will stimulate negative risk elsewhere in a contract, which might be in a different risk category (e.g. an information risk triggers the onset of a performance risk). Where widespread risk cascades within the contract, through the complex interconnection of its parts, then the contract is thought to have fallen victim to a pattern of systemic risk. 
Systemic risk relates to the complex interdependencies of risk that may prevail within a system. When risks behave in this way, a complex chain of outcomes may be formed which cascade through multiple parts of the system, or in extreme cases, has the capacity to impact on the entire system. The term "systemic risk" is one that has multi-disciplinary roots, with great acknowledgement from the economic and financial arena in response to the 2007-2008 global financial crisis (De Bandt et al., 2009). Further afield in the medical sphere, Dorland's Medical Dictionary (2011, page 489) defines a systemic disease as: "one that affects a number of organs and tissues, or affects the body as a whole". In the project manager's governing standards, practical guidance for the management of systemic risk in projects is absent, yet early recognition is emerging within academic research. Ackermann et al. (2007) highlight the importance of causation as a characteristic of risk systemicity, as done in the other fields examined: "risks can be seen as a network of interrelated possible events, which may be referred to as 'risk systemicity'"' (page 40). Whilst reference to the term "systemic" is made in wide-ranging contexts, a level of commonality between the term's characteristics is evidenced, distinguishing the term and extending the risk management practice away from its independent-based methods and connotations.

In view of the interdependent or systemic characteristics of risk, measurement tools (such as the risk register) designed to measure individual risks provides limitation to project managers, particularly when managing large or complex projects. Systems thinkers acknowledge the complex nature of project risk and propose the application of a compounded approach for solving complex projects. Cabrera et al. (2015) argue that solutions to complex problems may only be gained through acknowledgement of the cooccurrence of simple rules, capturing the interdependencies that exist between the systems subcomponents. From this perspective, using a compounded approach when solving complex projects may be considered far more beneficial, as opposed to individual or isolated measurement (Williams, 2002; Eden et al., 2000). By encompassing a compounded measurement approach within a project's risk assessment, and applying this tool to the development of the governing contract, it is thought that the anticipation and mitigation of systemic risk may be achieved. Our prior discussion of contract risk posed that its definition is limited since it only accounted for the ultimate outcome failures of a contract. This coheres with the view that often risks are treated independently, and therefore fail to account for the underlying complexities, which often stimulate these negative risks. In this paper, we describe a novel method for mapping a contract's risk dynamics, which accounts for the interdependencies that may cause system-wide damage to a project. 


\section{Managing risk in public contracts}

Typically, a public contract is legal arrangement, which codifies laterally integrated allocations of rights between the public sector and the private sector. A public contract essentially attempts to legally defend the boundaries of the parties, organise the activities within the contractual framework, and, reflect on the design of relationships between the public and private actors in terms of their respective rights and obligations (e.g. funding, purchases, provision of services, and, provision of guarantees). At the same time, the security of rights within a public contract is synonymous with the commitment and capacity of government to enforce them, as well as with the general normative legitimacy of the established legal system.

In general, public contracting arrangements present unusual regulatory, liability and risk issues because their subject matter concerns the delivery of public services. Of particular interest are the various problems related to the sharing of risks between the parties. In public contracts, the procurement process may trigger embryonic risk. The occurrence and subsequent growth of risk is affected by a variety of factors, such as the size and complexity of the project, the number of parties entering the agreement, and whether the origins of the risk lie internally or externally to the project. Risk can be controlled by the contract itself, mainly through allocation mechanisms, but also through a number of techniques which aim to neutralise relevant risks within the contractual framework (e.g. mobilisation, step-in rights, and open-book contract management).

The impact that risk can have on the project objectives is often reflected in the drafting of the public contract. Both the private and public sector need to have a better understanding of the risks in order to achieve an equitable risk allocation and enable the project to deliver its envisaged outcomes. In fact, a fair and reasonable allocation of various risks is vital to the success of a public contract. If risks are inequitably or wrongly allocated beyond the capacity of the parties concerned, the underpinning public contract may not be suitably aligned with the intended outcomes of the project, and the latter is bound to fail. Under traditional public procurement, government bore all or most of the risks associated with the project. This was reflected in the criterion for contract award, which aimed to achieve the best possible price-quality ratio in public contracts, or "Value for Money". The private sector party to a public contract had no incentive to take on risk, therefore the underpinned project was supported by an unbalanced contractual 
frame. Modern contracts aim to share the risk, and balancing a contract in terms of its risks is an essential activity that is capable of enhancing the overall performance of the project.

The principle of mutualism in contract law necessitates a partnership approach between the public and the private sector. Risks allocation is central to that principle. Risk, for example, can be looked at from the perspective of the different parties concerned: the sponsors, the lenders, the government, and the users/clients of the project. Risk can also be grouped into categories according its type, its origin and its effects.

Furthermore, the success of a project underpinned by a public contract rests on the optimal allocation sharing of risk between the public and private sector, with each partner retaining the risk they are best placed to manage. The transfer of risk through the contractual framework often is the basis for the decision to deliver public services by a public contract as it sets forth the rights and obligations of the government and private actors in connection with the implementation of that contract. In response to this, the applicable legal regime should include regulatory provisions for market-based principles to be recognised within the contractual relations. This translates into the imperative of flexibility for both parties to allow for adjustments and paves the way for the adoption of incomplete contracts to cover any and every contingency or eventuality.

In public sector contracting, understanding the risk dynamics, such as the transfer of risk that underpins a contract may be considered to be a form of risk management. The transfer of risk involves the allocation or distribution of the risks inherent to a project between or among contracting parties. If carried out effectively, risk transfer does not grossly or inequitably allocate all risks to one single party, but instead places risk upon parties according to their ability to control and/or insure against risk. Additionally, effective risk management typically generates positive results on a project by improving project performance, increasing cost effectiveness and creating a good working relationship between contracting parties. In order to account for these positive results, risk allocation within the context of public contracts should be established at the point of contract drafting. Ideally, during this initial phase, the parties will assign the risks and liabilities to the party best equipped to manage and minimise them. The contracting process provides the vehicle for each party to negotiate, define and limit its rights in accordance with its goals, and therefore, the risks and responsibilities associated with a specific project must be clearly allocated within the contract. In the end, the contract serves as a legislative framework between the 
parties and will establish which party has assumed or negated a particular risk in connection with the project.

\section{This study}

This paper results from a study that was undertaken on behalf of the Defence Science and Technology Laboratory (Dstl), an executive agency of the UK's Ministry of Defence (MoD) that ensures that innovative science and technology contribute to the defence and security of the UK. The study investigated a sample of the MoD's service commissioning projects, which entail the management of many risks, such as contractual, relational, organisational and technical complexity. Major complex defence projects are characterised by inherent complexity arising from challenges of scale, technological/contextual uncertainty, temporal and geo-spatial span, and attendant economic and political drivers / constraints. This study aimed to address the problem of defining the systemic risk associated with outsourcing strategies for such projects, and determining the efficacy of extant instruments for addressing this. The main instrument, of course, is the contract. Contracting is at the core of MoD's risk management practice. It was felt that traditional contracting could be improved to better understand and mitigate systemic risk in such projects. This study aimed to understand the issues, both in principle and in practice by looking at a sample of case studies, and considering whether the associated contractual mechanisms, relational structures and governance mechanisms could be enhanced.

\section{A method for analysing interdependent risk}

Although there have been recent contributions towards defining risk within the context of contracting (Haapio and Siedel, 2017), extant research on the topic has failed to identify and address the critical relationship between the structuring of a contract and its propensity to induce risk. We propose a method, which considers this aspect, through examination of the contract in terms of its risk category allocations, its underlying dynamics, and structure. The formal contract is a static representation of the project, encasing the intentions of the contract and setting its legal parameters. Through dissection of the contract, we can begin to identify the intent of the contract by examining the extent to which the contract's clauses protect against risk. 
To aid the risk identification process adopted when categorising the type of risk inherent to a contract, we define a contract's risk as comprising of four broad categories: representational, performance, finance, and/or contract risk. Representation risk may be reduced into two sub-categories, 'information risk' and 'relational risk', and is therefore grounded on the presence of information symmetry and cooperation in the contractual arrangement's inter-organisational and intra-organisational relationships. Performance risk relates to both the interim outputs and ultimate outcomes of the contract (e.g. the contracted deliverables and end product) and is often exacerbated by the onset of unanticipated issues associated with balancing the project's scope within the pre-defined time and budget constraints. Finance risk refers to an umbrella term, for which a number of forms of risk associated with the behavioural response to fiscal mechanisms and their outcomes can be incorporated. In public contracts, characteristics attributed to this category may include, but are not restricted to financial transactions, risk of default, remuneration, pricing, and, penalties. Finally, the fourth risk category: contract risk, refers to the probability of loss arising from a party reneging on the contract, as opposed to their inability to pay or deliver. Therefore, contract risk may arise where the contracting authority's protection clauses have reason to be executed. By adopting the proposed definitions, and subsequently, allocating a risk label to each of the contract clauses, a quantitative picture may be extracted that is capable of documenting the frequency of each risk category on the contract (which implies the weight or importance of that category). In doing so, the investigator is able to ascertain a preliminary view that indicates the types of risk that are prioritised by the contract writer, at the time of writing.

Whilst this initial phase of the contract dissection provides a snapshot of the contract's priorities, on its own, the relative frequency of risk categories provides little insight into whether these align with the anticipated outcomes of the contract. Following this logic, by merely reading through a contract and allocating a risk category to each contractual condition, the investigator can only form a partial understanding of the contract's purpose, as presented by the written contract. Taking an example, following the aforementioned coding process, if a significant proportion of representation risk was identified within the contractual terms and conditions, one might infer that perhaps the contract has been structured in a way that facilitates a collaborative relationship to be formed between the parties. Whilst this may be considered to be a fairly rational assumption, there may be a multitude of other reasons for reinforcing a contract with considerable emphasis on its representation risk categorisations (it could be that the two parties have not participated in regular course of dealing, and therefore the contract reflects a priority concerning the protection of information). 
The benefit of the risk categorisation process is therefore lost without consideration of how the contract is playing-out in actuality (i.e. as it progresses through the project life cycle). In addition to the undertaking of an initial coding process, further information can be gained by conducting semi-structured interviews with the key personnel involved in managing the contract, from both sides. Through the incorporation of these recorded interviews, any early assertion made during the dissection of the contract may be compared against the information provided by participants. Adoption of this multi-method process therefore enables valuable insights to be gained in terms of whether the discourse of the written contract aligns with the intended outcomes that were set at the front-end of the project. The alignment of risk frequency with anticipated outcomes is achieved where visual patterns exposed during the contract mapping process, described in the following paragraph, are able to depict visually the overarching project aims. For example, if the contract aims to facilitate a balanced, collaborative relationship between the contracting parties, then the proposed visual mapping tool should illustrate this characteristic by displaying proportionate risk frequency to either party. If the written contract fails to align with the desired outcomes identified by the key personnel tasked with managing the contract, then the contract may inhibit the project's attainment of outcomes, and the contract becomes increasingly susceptible to systemic risk. At this stage, the duo of methods (contract analysis and interviews) adopted for determining the risk landscape embedded into the contract satisfies the definition set by Haapio and Siedel (2017), in that it shows how a contract may deviate away from the expected outcomes of the contracting parties through misalignment between the risk priorities embedded in a contract and its pre-defined outcomes.

As already maintained, when determining the riskiness of a contract, by identifying the types of risk written into the contract, insights into whether the construction of the contract is deemed to have been written comprehensively enough or whether it contains a structural defect in the risk management design, can be obtained. On its own, the aforementioned risk categorisation technique may exhibit limitations, in that it disregards the interdependent nature of risk. To account for the way in which the risk profile evolves over the timeframe of the project, we have developed a visual risk mapping tool that extends the risk categorisation process initially undertaken (Figure 1). Having identified the risk associated with meeting the ultimate outcome of the contract, the risk mapping tool enables a more detailed analysis of how the contract's ex-ante risks are distributed both in terms of: the distribution of the contracting parties' risk allocation, and the interconnectivity of risk across the pre-constructed contract architecture. 
It should be noted that the tool currently treats all risk interconnections equally, without recognising the difference in importance between risks (which requires human judgement).

A key feature of the developed risk migration mapping technique is its ability to provide a visual representation of the risk transfers that occur between the contracting parties. By determining which party the majority of risk resides with, we can begin to understand the intentions of the contract. Within it, the contract will explicitly state the responsible owner of a certain obligation. Every condition is therefore made up of a set of clauses that transfer a level of responsibility onto either of the contracting parties (e.g. "the Contractor shall..."). Where responsibility is placed exclusively within the remit of one contracting party, that party assumes an element of risk. Providing a specific example of a single risk migration, a common condition to transfer risk solely towards the contractor is in the "Contractor's Obligations" or its direct equivalent.

In some cases, such as in traditional contracting, a heavy migration of risk from the contracting authority towards the contractor might be intentional and therefore characteristic of this mechanism. However, in cases where the intent of the contract resides under relational contracting classification, this may not be the case. Take for example, a contract that aims to deliver a collaborative outcome between the parties. Given that such a contract is underpinned by an objective to develop a collaborative relationship between the customer authority and the contractor, predicated on inter-party cooperation, a risk-sharing feature would be expected. It would be anticipated that such a contract would contain a reasonably balanced set of obligations, with contractual onus on both parties and that this would be replicated visually on the riskmapping tool through proportionate linages above the horizon and below the horizon of the diagram (Figure 1). In reality however this is not always the case, and risk flows may travel disproportionately from the contracting authority towards the contractor. In other words, if the contract writer does not construct the consolidated contract to align with the core pre-identified contractual requirements, then the outcomes of that contract are unlikely to be met. This feature of migration mapping therefore builds on the initial phase of risk analysis by providing a further depiction of the effectiveness of the contracting mechanism being used. 


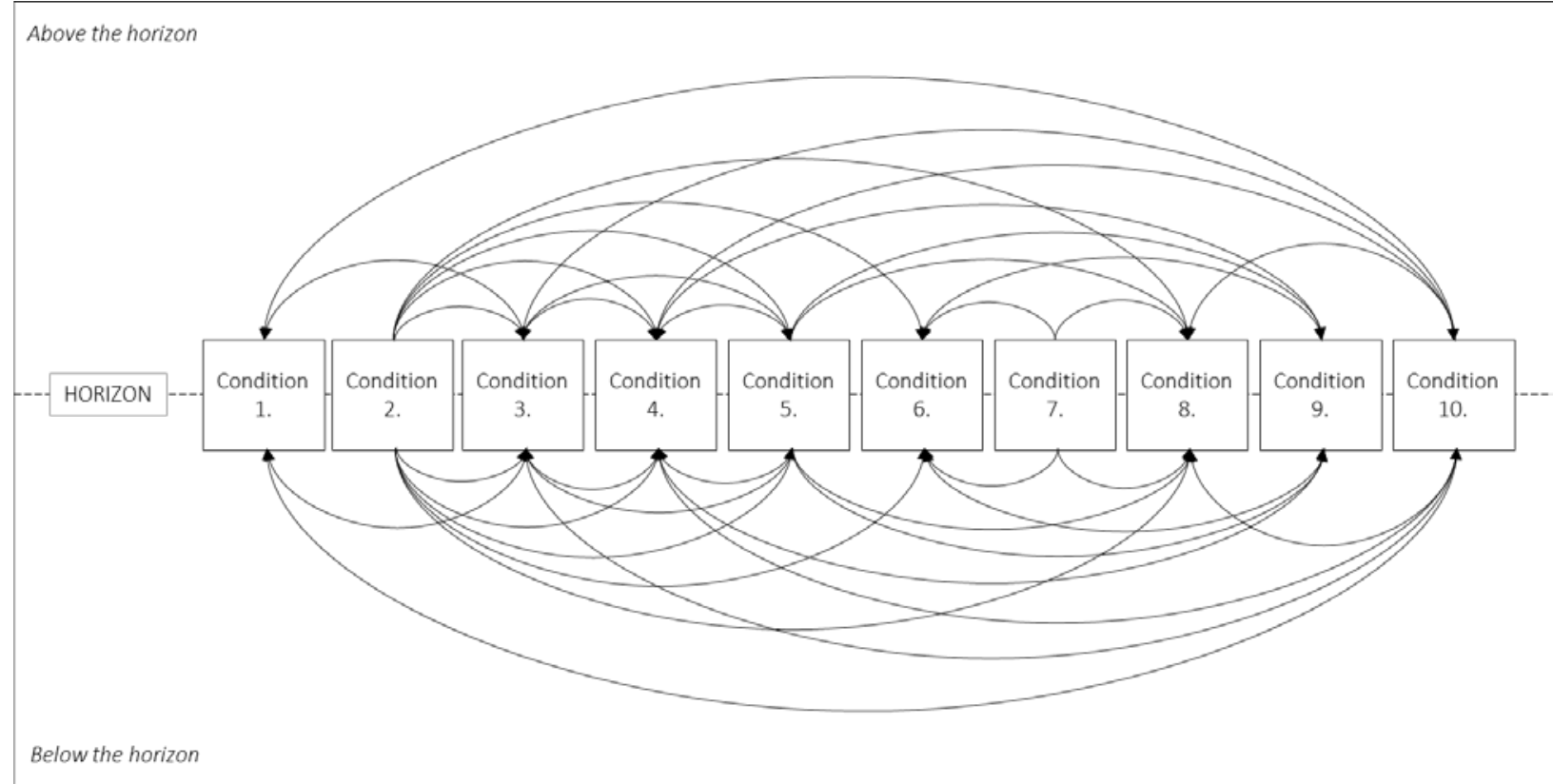

Figure 1: A simplified risk-mapping prototype depicting a balanced allocation of risk between the contracting parties.

The second feature of interdependent risk, capable of being illustrated using the risk-mapping tool, is the transfer or migration of risk from one contract condition to another. Throughout a contract, the terms and conditions (inclusive of any binding schedules or annexes) continually cite clauses, which contain some degree of shared meaning in a bid to achieve contractual cohesion and robustness. The mapping tool illustrates the interconnectivity that exists between the contract clauses through the use of directional arrows, the directional flow of which can be traced from the origin of the arrow, towards the arrowhead. Where risk arises in one condition, those that bear close relations are susceptible to undergoing a knock-on effect; a feature which has the propensity to cascade along multiple components of the contractual clauses, demonstrating the systemic characteristics of contract risk (i.e. $x$ leads to y).

Providing an example of this pattern for methodological clarity: where government impose initiatives aimed towards generating a more balanced price-quality (or 'value for money') ratio on its projects, the contract may contain a condition that imposes a legal obligation on the parties to regularly review the balance of price-quality achieved by the project (e.g. by including a Value for Money Review condition within the contract). Whilst this condition provides legal assurance that a regular review process must be undertaken to ensure value for money is achieved (eliminating some finance risk, among others), it contains weaknesses in terms of how the value for money solutions (e.g. changes to service specifications) can be implemented. Rather than trusting that the responsible party within the remit of this condition will effectively manage change, the potentially harmful risk might be transferred to a separate condition that 
controls the procedure for contractual amendments (i.e. the Contract Change Control Procedure). In this way, closely interlinking conditions can be seen to transfer features of risk between the contracts' conditions.

\section{Applying the method to public sector contracting}

This method for understanding the risk inherent within a contract was one that was developed through the examination of a number of MoD projects, and further expanded upon its application to the project's supporting contracts. Public sector contracts are governed by an over-riding procurement policy and are primarily concerned with achieving best value for money, through competition. The contracts designed to achieve this objective (or any other objective), must therefore be carefully constructed to ensure that its contracts successfully fulfil the requirements set by government policy. Failure of a contract to align with policy, also foregoes its intended contractual outcomes, and when defects such as these occur, the public sector department responsible can experience heavy repercussions. The most severe consequences appear in contracts that are available to the public through freedom of information, are large in value, or have a wide end-user reach, giving them the capability to become extremely politically charged.

Public sector outsourcing projects are regularly reported in the media, where contract failures become unrecoverable, resulting in termination, or where estimates of costs and/or performance are vastly exceeded. The risks provoking such catastrophic failure in public sector outsourcing projects therefore provided the impetus to investigate risk to a contract. The methods previously described were applied to a set of on going service contracts, which comprised a broad range of both specialist and non-specialist service areas. Each contract underwent dissection and analysis independently, before the data was analysed for its common themes, providing insight to the way that services are contracted for within this public sector department. Through adoption of the method, structural disconnects were found between the contract and the contractual objectives. Some contractual mechanisms were envisioned to be relational contracts, grounded by inter-party collaboration and all engagements with industry bidders and the contractor selected reflected this understanding. There was however, disparity between the contract's intended outcomes and the way in which the terms and conditions were structured within the contracts. In all cases, where outcomes were misaligned, the contract experienced connected issues, triggered by other risk categories. An example of this would be the effects that this could have on the 
relationships between the two parties and their trust and willingness to transfer information required for the performance of the contract.

Risk was further evidenced to have indicated how effective the contract was when supporting the mobilisation phase of the contract. The mobilisation phase of a contract refers to the period of time that begins where a contractor is tasked with delivery (bidder selection), up until the point of the formal contract commencement (the contract start date). The timeframe allocated to mobilisation is crucial for the early implementation and management of the contract and if sub-optimal, the performance of the contract during its early life can become negatively affected by the onset of risk. Mobilisation is not a process that is explicitly written into a contract's terms and conditions, however it can be identified through close inspection of the dynamics of risk mapped using the visual tool. In many cases, it became apparent that the visualisations depicted patterns that constitute a front-loaded contract spine. When plotting a risk migration map, a 'front-loaded contract spine' represents a visual pattern whereby a considerable volume of risk originates (with the capacity to migrate) within the early indexed conditions, across the contract. In other words, a risk that originates in the front sections of the contract often has the capacity to interlink with the conditions positioned in later sections of the contract. Where a heavy density of risk appears to be front-loaded, one would infer that a comprehensive contract mobilisation is required to prevent risk. In other words, a significant clustering of risk towards the front-end of the contract spine (i.e. a contract spine that is densely populated with directional arrows) would suggest that the contract would benefit from incorporating an effective mobilisation phase. In this case, an effective mobilisation would be one that allocates sufficient resources (e.g. appropriate materials, labour, and time allowances) to the project, so that all essential infrastructure is completed at the time of contract commencement.

The practice of front-loading risk in contacts, especially public contacts is habitual in contract drafting. Evidence is substantiated by reference to General T\&Cs or Special T\&Cs, which reflect the risk concern of the contracting authority and are often set $a b$ initio as non-negotiable provisions. Front- loading (risk) can visually occur by locating the risks (in our case, the T\&Cs) at the beginning of the contract document, or by reference to the annexes/appendices, a practice called "backing". Of course, the migratory movement of risk will originate where the contract exhibits a front-loaded structure and reflects on the parties' attempt to balance the contract as close to their favour as possible. In addition to this, front-loaded risk is also natural to the drafter of the contract, who seeks to have (early) visibility of potential breaches. 
Front-loading of a contract by the contracting authority therefore aligns with the concept of sequential ordering, where the contract writer, reflecting the density of those probable risks that must be managed against, prioritises the conditions that make up the contract. The higher the density of probable risk, the more likely it is to be positioned towards the front of the contract spine. Whilst it appears logical to order the contract sequentially, thereby front-loading the contract with risk management clauses, what must be considered is the fact that; whilst the contract may contain provisions to manage risk, the underlying threat of risk materialisation is not totally eradicated. Where risk materialises, there is a threat that these front-loaded risks will have a cascading effect further down the contract. In cases where risk cannot be retained in a localised manner through careful management or through the enforcement of pre-empted contractual solutions, further complications or risks may be stimulated. In cases such as these, risks that are not bounded, localised risks (i.e. those that are unanticipated) have the capacity to infringe on the contract until a system-wide or systemic risk pattern emerges.

\section{Conclusion}

In this special issue of the International Journal of Forecasting, the emphasis of risk and uncertainty is explored. Our research aims to improve the capability of project stakeholders in forecasting the shortterm outputs and long-term outcomes of a major public project, by identifying the presence of systemic risk within the contract. The paper calls for new considerations to be taken into account when managing this risk. Through examination of the existing literature, in project management and other fields, it has become evident that the current risk management tools adopted in practice disregard the interdependent nature of risk, its human components, contextual complexity, and, the need to go beyond an oversimplified definition of uncertainty. This means that the common reputation of public projects is that their outputs (i.e. the immediate performance of the project) and particularly outcomes or benefits, are poorly forecast, and will often be late, over-spent, or not deliver the benefits for which they were set up.

A key instrument derived within a project's risk assessment phase, and a crucial feature to this paper is the formal contract, which comprehends and governs a project's risk. We take the stance that, if a contract is constructed in a way that ensures that its incorporated legal provisions are closely aligned with the predetermined outcomes of the project (as opposed to the short-term outputs), then the contract has improved capacity to administer effective risk mitigation. In line with this this assertion, the paper presents the novel development of a risk migration-mapping tool. The tool aims to contribute a new method of early risk identification that is capable of being undertaken during the contract's drafting 
process in order to prevent systemic risk from propagating throughout the project. The tool therefore offers a new method, which may be employed by a project's stakeholders during the initial scoping and set-up of the project. By incorporating the risk migration tool within the project set-up, it is hoped that the project team (particularly the Senior Responsible Owner but also project managers, commercial management, finance management, and so on) will enhance both their understanding and awareness of the potential risk dynamics to which a project may be susceptible. It is hoped that this will both enhance the ability to forecast the behaviour of the project under the specific contract, as well as enhance the capability of the public authority to take a view of the overall systemic risk of a contract.

Extending beyond the theoretical rationale, the tool presented in the paper has undergone testing and development using a sample of live public outsourcing contracts, obtained from the UK's Ministry of Defence. By applying this new approach to major public contracts, our findings reinforce our earlier claims that project managers (tasked specifically with managing the risk assessment process) would benefit from implementing more appropriate methods of risk analysis that account for the dynamic and systemic nature of risk and its capacity to impose risk on a contract in systemic proportions. 


\section{References:}

Ackermann, F., Eden, C., Williams, T., \& Howick, S. (2007). Systemic risk assessment: a case study. Journal of the Operational Research Society, 58(1), 39-51.

Association of Project Management. (2004). Project Risk analysis and Management Guide. 2nd edition. High Wycombe, UK: APM Publishing Ltd.

Association for Project Management. (2008). Prioritising Project Risks. Princess Risborough, UK: Association for Project Management.

Breese, R., Jenner, S., Serra, C. E. M., \& Thorp, J. (2015). Benefits management: Lost or found in translation. International Journal of Project Management, 33(7), 1438-1451.

Cabrera, D., Cabrera, L., \& Powers, E. (2015). A unifying theory of systems thinking with psychosocial applications. Systems Research and Behavioral Science, 32(5), 534-545.

De Bandt, O., Hartmann, P., \& Peydró, J. L. (2009). Systemic risk in banking. In The Oxford handbook of banking.

Department of Defense. (2002). DoD News Briefing - Secretary Rumsfeld and Gen. Myers February 12, 2002 11:30 AM EDT. http://archive.defense.gov/Transcripts/Transcript.aspx?TranscriptID=2636 downloaded $24^{\text {th }}$ April 2018.

Dorland, W. A. N. (2011). Dorland's Illustrated Medical Dictionary, Elsevier Health Sciences.

Eden, C., Williams, T., Ackermann, F., \& Howick, S. (2000). The role of feedback dynamics in disruption and delay on the nature of disruption and delay (D\&D) in major projects. Journal of the Operational Research Society, 51(3), 291-300.

Eden, C., Ackermann, F., \& Williams, T. (2005). The amoebic growth of project costs. Project Management Journal, 36(1), 15-27.

Edkins, A., Geraldi, J., Morris, P., \& Smith, A. (2013). Exploring the front-end of project management. Engineering Project Organization Journal, 3(2), 71-85.

Flyvbjerg, B., Bruzelius, N., \& Rothengatter, W. (2003). Megaprojects and risk: An anatomy of ambition. Cambridge University Press.

Geraldi, J., Maylor, H., \& Williams, T. (2011). Now, let's make it really complex (complicated) A systematic review of the complexities of projects. International Journal of Operations \& Production Management, 31(9), 966-990.

Haapio, H., \& Siedel, G. J. (2017). A short guide to contract risk. Routledge: London.

International Institute of Forecasters. (2018). IJF Special Issue: Forecasting, Uncertainty and Risk Management: Call for papers. https://forecasters.org/blog/2016/08/10/ijf-special-issueforecasting-risk/, Downloaded 24 April 2018. 
Keil, M. (1995). Pulling the plug: Software project management and the problem of project escalation. MIS quarterly, 421-447.

Keil, M., \& Mähring, M. (2010). Is your project turning into a black hole?. California Management Review, 53(1), 6-31.

Morris, P. (2011). Managing the Front-End: Back to the beginning. Project perspectives, 33, 4-9.

Narayanan, V. K., \& DeFillippi, R. (2012). The influence of strategic context on project management systems: a senior management perspective. In Project Governance (pp. 3-45). Palgrave Macmillan, London.

IPA. (2017). Annual report on Major Projects 2016-2017. https://assets.publishing.service.gov.uk/government/uploads/system/uploads/attachment dat a/file/629622/IPA Annual Report 2017.pdf, Downloaded 16 Apr 2018.

IPA. (2018). Quote from Project X website. https://www.bettergovprojects.com/, Downloaded 16 Apr 2018.

Leitch, M. (2010). ISO 31000: 2009 - The new international standard on risk management. Risk analysis, 30(6), 887-892.

Midler, C. (1995) "Projectification" of the firm: The renault case, Scandinavian Journal of Management, Volume 11, Issue 4, 363-375

Miller, R., \& Lessard, D. R. (2001). The strategic management of large engineering projects: Shaping institutions, risks, and governance. MIT press.

National Audit Office. (2013). Over-optimism in Government Projects. Downloaded from https://www.nao.org.uk/wp-content/uploads/2013/12/10320-001-Over-optimism-ingovernment-projects.pdf, Downloaded 19 Jun 2018.

O'Leary, T., \& Williams, T. (2013). Managing the social trajectory: a practice perspective on project management. IEEE Transactions on Engineering Management, 60(3), 566-580.

Oaks, M. (1986). Statistical inference: A commentary for the social and behavioral sciences, Wiley: New York.

PMI. (2017). A cross-national comparison of benefits management practices. Unpublished report submitted at the Project Management Institute 2017. Authors T. Williams et al.

Project Management Institute. (2009). Practice Standard for Project Risk Management. Newtown Square, PA, US: Project Management Institute.

Project Management Institute. (2013). A Guide to the Project Management Body of Knowledge (PMBOK) 5th Edition. Newtown Square, PA, US: Project Management Institute 
Ramasesh, R. V., \& Browning, T. R. (2014). A conceptual framework for tackling knowable unknown unknowns in project management. Journal of Operations Management, 32(4), 190-204.

Samset, K. (2010). Early project appraisal: making the initial choices. Palgrave Macmillan, UK.

Shafer, G. (1976). A mathematical theory of evidence (Vol. 42). Princeton university press, US.

Taleb, N.H. (2008). The Black Swan: The Impact of the Highly Improbable. London: Penguin.

Thamhain, H. (2013). Managing risks in complex projects. Project management journal, 44(2), 20-35.

Williams, T. M. (1994). Using a risk register to integrate risk management in project definition. International Journal of Project Management, 12(1), 17-22.

Williams, T. (2002). Modelling complex projects. Chichester: Wiley.

Williams, T.M. (2017). The Nature of Risk in Complex Projects. Project Management Journal. 48 (4) 55-66.

Williams, T. \& Samset, K. (2010). Issues in front-end decision-making on projects. Project Management Journal. 41 (2), 38-49.

Williams, T. Vo, H. Samset, K. \& Edkins, A. (2018). The front-end of projects - structuring using a PMI literature survey. To be given at Concept Symposium 2018, Stavangar, Sept 2018.

World Bank. (2018). Downloaded from World Bank website: https://data.worldbank.org/indicator/NE.GDI.FTOT.CD?end=2016\&start=1960, Downloaded 17 Apr 2018. 